Logos. Anales del Seminario de Metafísica

ISSN: 1575-6866

http://dx.doi.org/10.5209/asem.70833

\title{
Neurociencia, Humanismo y Posthumanismo
}

\author{
Emilio García García ${ }^{1}$
}

Recibido: 14 de noviembre de 2019 / Aceptado: 26 de abril de 2020

Resumen. Durante las últimas tres décadas, la Neurociencia ha logrado avances espectaculares, pero la investigación tiene ante sí graves retos. Comentamos proyectos actuales de investigación neurocientífica, como el Proyecto Conectoma, el Proyecto Brain, y el Human Brain Proyect. Estudiamos la confluencia de las tecnologías biomédicas e ingeniería genética con la inteligencia artificial y computación, y el impacto que tienen en el conocimiento del mundo exterior y de nosotros mismos. Identificamos potencialidades y amenazas de las nuevas tecnologías y la contribución a la conformación del pensamiento posthumanista.

Palabras clave: neurociencia; humanismo; transhumanismo; posthumanismo; cerebro; mente; cultura.

\section{[en] Neuroscience, Humanism and Posthumanism}

\begin{abstract}
During the last three decades, Neuroscience has made spectacular progress, but research has serious challenges. We discuss current neuroscientific research projects, such as the Conectoma Project, the Brain Project, and the Human Brain Project. We study the confluence of biomedical technologies and genetic engineering with artificial intelligence and computing and the impact they have on the knowledge of the outside world and ourselves. We identify potentialities and threats of new technologies and the contribution to the formation of post-humanist thinking.
\end{abstract}

Keywords: neuroscience; humanism; transhumanism; posthumanism; brain; mind; culture.

Sumario. 1. Introducción; 2. Proyectos de investigación neurocientífica; 3. Neurociencia en el proyecto humanista; 4. Neurociencia y posthumanismo; 5 . Conclusiones; 6 . Referencias bibliográficas.

Cómo citar: García García, E. (2020) "Neurociencia, Humanismo y Posthumanismo”, en Logos. Anales del Seminario de Metafísica 53, 9-31.

\footnotetext{
$1 \quad$ Universidad Complutense de Madrid emiliog@ucm.es
} 


\section{Introducción}

En las últimas tres décadas vivimos inmersos en una revolución científica: la neurociencia. Los conocimientos del sistema nervioso, y particularmente del cerebro, han logrado tales desarrollos que pueden ser comparables a los avances en la física, a principios del siglo XX, y la biología en la década de 1950. El cerebro humano ha sido el protagonista de todas las revoluciones, ha logrado todos los conocimientos y saberes, las matemáticas, ciencias naturales, ciencias sociales, humanidades, tecnologías, artes. Pero el cerebro que conoce ha sido el gran desconocido. Ahora estamos avanzando en su estudio y comprensión. A diferencia de otras revoluciones científicas, que se han ocupado del mundo exterior, como física, biología o cosmología, la neurociencia centra su interés en nosotros mismos, nuestro cerebro, el órgano que hace posibles todas las demás revoluciones. La neurociencia nos proporciona una oportunidad nueva para comprender nuestra mente y comportamiento, la estructura y funciones del yo, no sólo observando la conducta desde el exterior, sino también gracias al estudio de la organización funcional del cerebro. Por primera vez en la historia, nuestra especie tiene la posibilidad de mirar hacia atrás y a sí misma, de entender sus orígenes y también conocer quién es el agente consciente y libre encargado de entender ${ }^{2}$.

La nueva revolución que estamos viviendo está caracterizada por el prefijo "neuro". Así, en el campo biomédico: neurobiología, neuroanatomía, neurología, neurofisiología, neuropsicología, neuropsiquiatría, neurofarmacología. En las ciencias sociales, neuroderecho, neuropolítica, neurocriminología, neuroeconomía, neurosociología, neuromarketing, neuropedagogía, neurodidáctica, neuroeducación, neurocultura. En la filosofía y las humanidades, neurofilosofía, neuroepistemología, neuroéstetica, neuroética, neurorreligión, neurofenomenología, neurodeterminismo, neurorrealismo, neuroesencialismo, neuroexistencialismo. Si el cerebro es la base de los procesos mentales y las actividades humanas, no es de extrañar que en las diversas ciencias de la vida, de la sociedad, y las humanidades, la perspectiva de la neurociencia sea omnipresente y surjan nuevos campos de estudio ${ }^{3}$.

El término de neurociencia es relativamente reciente. La Society for Neuroscience, la asociación pionera y más representativa de neurocientíficos, se fundó en 1969. Tiene como objetivos: avanzar en la comprensión del cerebro y el sistema nervioso; proporcionar actividades de desarrollo profesional, información y recursos educativos; promover la información y educación del público sobre la neurociencia; informar a los legisladores y otros responsables políticos acerca de las implicaciones de la investigación para las políticas públicas, beneficios para la sociedad, y el continuo progreso científico.

Los científicos dedicados al estudio del sistema nervioso procedían de disciplinas distintas como matemáticas, física, química, biología, medicina, psicología. La revolución de la neurociencia surgió cuando estos científicos constataron que los mejores planteamientos para comprender la estructura y el funcionamiento del cerebro eran los enfoques interdisciplinarios, procurando nuevas perspectivas,

2 Changeux, J. P.: Sobre lo verdadero, lo bello y el bien. Un nuevo enfoque neuronal, Madrid, Katz, 2010; Ramachandran, V.: Lo que el cerebro nos dice, Barcelona, Paidós, 2012.

3 Cortina, A.: Guía Comares de Neurofilosofía práctica, Granada, Comares, 2012; Mora, F.: Neurocultura, Madrid, Alianza, 2007; Illes, J.: "Neurologisms", American Journal of Bioethics, 9, 9, 1, 2009. doi: $10.1080 / 152651609031192557$. 
metodologías y síntesis teóricas. En la neurociencia se distinguen varios niveles de análisis, que en orden ascendente de complejidad comprenden: el nivel molecular, celular, circuitos neuronales, redes y sistemas. La neurociencia molecular estudia la complejidad molecular del sistema nervioso y las diversas moléculas que lo componen y desempeñan distintas funciones en el cerebro, particularmente los neurotransmisores. La neurociencia celular presta atención al estudio de cómo todas estas moléculas trabajan juntas, suministrando a las neuronas sus propiedades especiales y plantea cuestiones como los tipos diferentes de neuronas y sus funciones, los procesos de neurogénesis y la sinaptogénesis. La neurociencia de sistemas estudia los circuitos y redes neuronales complejos que llevan a cabo una función común, por ejemplo, visión, movimiento, lenguaje. La neurociencia cognitiva investiga los procesos neuronales que están a la base de los niveles superiores de la actividad mental humana, como son la conciencia de sí mismo, el lenguaje, la imaginación, la creatividad, el sentido estético, el comportamiento moral ${ }^{4}$.

Desde la neurociencia se interpreta los procesos mentales como una conquista evolutiva de los organismos $\mathrm{y}$, tratándose del ser humano, de la interacción entre genes, cerebro y cultura. Nuestra especie humana ha desarrollado unas capacidades cognitivas, emocionales, lingüísticas y sociales singulares, que le han permitido la comunicación e interacción social, la creación y transmisión de la cultura y el desarrollo personal. La capacidad de empatía, cooperación y altruismo, la capacidad de atribuir mente a los demás, de interpretar y predecir la conducta de los otros, y colaborar para lograr objetivos compartidos (también engañar), posibilitan el desarrollo personal y la evolución sociocultural. Junto con la capacidad de empatizar y colaborar los humanos hemos conseguido, gracias al lenguaje compartido, generar relatos, imaginar otros mundos, construir ficciones, adentrarnos en territorios inexplorados, lo que es básico para la vida en sociedad y desarrollo cultural. A su vez, las conquistas culturales, artefactos, símbolos, tradiciones, instituciones y normas, constituyen el medio natural para el desarrollo personal.

El cerebro-mente es resultado de un largo y complejo proceso evolutivo. En la perspectiva filogenética, a lo largo de millones de años, surgieron unas capacidades cognitivas y sociales exclusivas de la especie humana. La capacidad de atribuir estados mentales a los otros y reconocer las peculiaridades de los estados mentales propios, permite planificar y valorar las consecuencias de las acciones. Esta capacidad mentalista posibilita la intersubjetividad, el comportamiento social y moral ${ }^{5}$. Esta nueva capacidad de comprender a otras personas cambió radicalmente el proceso de evolución cognitiva, y la naturaleza de las interacciones sociales, dando lugar a una forma singular de evolución cultural. Es el llamado "efecto trinquete" o "bola de nieve". Los seres humanos han generado una dinámica de normas sociales para lograr objetivos y resolver los problemas de vivir en sociedad ${ }^{6}$.

El descubrimiento de las "neuronas espejo" ha proporcionado conocimientos sobre las bases neurales de las capacidades mentales. Las neuronas espejo son un tipo particular de neuronas que se activan cuando un individuo realiza una acción, pero también cuando observa una acción similar realizada por otro individuo.

4 Bear, M, Connors, B. y Paradiso, M.: Neuroscience, exploring the brain, Philadelphia, Lippincott Williams, 2016.

5 García García, E.: "Desarrollo de la mente: filogénesis, sociogénesis y ontogénesis”, en M. Maceiras y L. Méndez (eds), Ciencia e investigación en la sociedad actual, Salamanca, San Esteban, 2010, pp. 95-128.

6 Tomasello, M.: Los orígenes culturales de la cognición humana, Buenos Aires, Amorrortu, 2007. 
No necesitamos realizar razonamientos lógicos para comprender la mente de los otros; las neuronas espejo nos permiten comprender las intenciones, sentimientos y comportamientos de otras personas con sólo observar sus acciones. En los comienzos de la década de 1990, un equipo de neurobiólogos italianos, dirigidos por G. Rizzolatti, de la universidad de Parma, se encontró con unos datos inesperados en el transcurso de la investigación con monos macacos. Tenían microelectrodos implantados en la corteza premotora del cerebro, para registrar la actividad eléctrica de las neuronas, cuando los monos mostraban ciertos comportamientos, como agarrar un palo o comer una uva. En determinada ocasión sucedió algo desconcertante, al activarse de pronto el aparato de registro sin que el mono realizase ninguna actividad. Las neuronas se activaban sin que el mono moviera un solo dedo. Bastaba con que viera que otro realizaba tal acción. Los científicos italianos habían identificado un tipo de neuronas desconocidas hasta ese momento, las denominaron neuronas espejo ${ }^{7}$.

Las neuronas espejo forman parte de un sistema de redes neuronales que posibilita la percepción-ejecución-intención-emoción-comunicación. Cuando una persona realiza acciones en contextos significativos, tales acciones van acompañadas de la captación de las propias intenciones que motivan a hacerlas. Se conforman sistemas neuronales que articulan la propia acción asociada a la intención. Formadas estas asambleas neuronales de acción-ejecución-intención en un sujeto, cuando ve a otro realizar una acción, se provoca en el cerebro del observador la acción equivalente, evocando a su vez la intención y emoción con ella asociada. El sujeto, así, puede atribuir a otro la intención que tendría tal acción si la realizase él mismo. Cuando se ve a alguien realizando una acción automáticamente se simula la acción en el cerebro. Si se comprende el significado de la acción de otra persona es porque se dispone en el cerebro de unas redes neurales que representan tal acción ${ }^{8}$.

La publicación de estos resultados desató un entusiasmo desbordante, no exento de polémica entre los especialistas. Ramachandran llegó a profetizar que tal descubrimiento de neuronas especulares estaba llamado a desempeñar en psicología un papel semejante al que había tenido en biología la decodificación del ADN. Por primera vez se había encontrado una conexión directa entre percepción y acción, que permitía explicar muchos fenómenos en polémica, particularmente la empatía y la intersubjetividad. Las neuronas especulares posibilitan al hombre comprender las intenciones de otras personas y también compartir sus emociones. Le permite ponerse en lugar de otros, leer sus pensamientos y sentimientos, lo que resulta fundamental en la interacción social y comportamiento moral. La comprensión interpersonal se basa en que captamos las intenciones y motivos de los comportamientos de los demás. Para lograrlo los circuitos neuronales simulan subliminalmente las acciones que observamos, lo que nos permite identificarnos con los otros, de modo que actor y observador se hayan en estados neuronales muy semejantes. Las neuronas espejo permiten entender la mente de nuestros semejantes, no a través de razonamiento, sino directamente, sintiendo y no pensando.

7 Rizzolatti, G.: “The mirror neuron system and imitation”, En S. Hurley y N. Chatter (comp.). Perspectives on imitation: from neuroscience to social science, Cambridge MA, MIT Press, 2005; Rizzolatti, G. y Sinigaglia, C.: Las neuronas espejo, Barcelona, Paidós, 2006.

8 García García, E.: "Neuropsicología y educación. De las neuronas espejo a la teoría de la mente", Revista de Psicología de la Educación, 1, 3, 2008, pp. 68-89. 


\section{Proyectos de investigación neurocientífica}

Las investigaciones en neurociencia se realizan con tecnologías muy complejas y sofisticadas según los diferentes niveles de análisis, desde el nivel más micro al macro. En la actualidad hay ambiciosos proyectos en marcha: Proyecto Conectoma Humano y Proyecto BRAIN, ambos en EEUU, y Proyecto Cerebro Humano, en Europa. El objetivo común es conocer más sobre la estructura y organización funcional del cerebro, cartografiar o mapear el cerebro y lograr la descripción más completa posible de su estructura y funcionamiento a los distintos niveles señalados. En otros países, particularmente China, Japón o Australia se desarrollan macroproyectos similares. Se estima que hay más de 10.000 institutos, laboratorios y centros de investigación en neurociencia, y las publicaciones anuales sobre la materia superan las 60.000, en todo el mundo.

El Proyecto Conectoma, aprobado y financiado por varias instituciones y organismos de EEUU, está patrocinado por los Institutos Nacionales de la Salud de los Estados Unidos y se propone identificar y mapear las conexiones y redes neuronales del cerebro. El nombre conectoma, identificación y mapeado de conexiones, evoca el genoma, referido a los genes, o el proteoma referido a las proteínas. El proyecto es muy ambicioso y necesita avances en las tecnologías para su conclusión, lo que ya se están logrando en parte ${ }^{9}$. La complejidad del cerebro es impresionante, con cien mil millones de neuronas, una media de 10.000 conexiones por neurona, lo que nos da mil billones de conexiones. Se ha estimado que la longitud de los axones llegaría a $150.000 \mathrm{~km}$. En el Proyecto Conectoma participan equipos de investigación de numerosas universidades y países, Universidad de Washington, Minnesota, Oxford, Londres, Nimega, entre otras, con el objetivo de cartografiar la totalidad de conexiones nerviosas en el cerebro, y también la relación entre genes, conectoma, procesos mentales y comportamiento. Las tecnologías de investigación más utilizadas hasta el momento son la resonancia magnética funcional, la resonancia magnética de tensor de difusión y la magnetoencefalografía.

Diversas investigaciones han confirmado que cada persona dispone de un perfil de conexiones característico, y que estos neuroperfiles personales pueden revelar información sobre las capacidades mentales, el funcionamiento normal o alterado. En un estudio realizado por varios autores, de distintas universidades y países, publicado en la prestigiosa revista Nature $^{I 0}$, se definen distintas regiones en la corteza cerebral, utilizando una combinación de técnicas que hasta el momento solo se habían empleado por separado: la resonancia magnética funcional basada en tareas, la resonancia magnética funcional en estado de reposo, y la resonancia magnética por tensor de difusión. El resultado ha dado una cartografía cerebral que identifica 180 áreas en cada hemisferio, lo que proporciona, por tanto, un atlas del cerebro humano con 360 zonas. Estas regiones podrían subdividirse además en unidades menores. La aparición de nuevas tecnologías con mayor sensibilidad proporcionará información de nuevas áreas.

Una gran innovación del estudio está en proporcionar un algoritmo para delinear áreas corticales a escala individual, que es una tarea más compleja que lograr un mapa

\footnotetext{
https://www.humanconnectomeproject.org

10 Glasser, M. et al.: "A multi-modal parcellation of human cerebral cortex", Nature, 536, 2016, pp. 171-78. doi:10.1038/nature 18933
} 
medio del cerebro. Este planteamiento proporcionará conocimiento importante para determinar biomarcadores de disfunción y trastorno cerebral, y al mismo tiempo un valor predictivo de las diferencias individuales en la conducta normal y patológica, $\mathrm{y}$ en las disfunciones y trastornos mentales. Tendremos una neurociencia cada vez más orientada al individuo, más personalizada. Si la neuroplasticidad hace posible los aprendizajes y memorias, podemos decir que somos nuestro conectoma. Al igual que todos tenemos un genoma específico y diferencial, también disponemos de un conectoma, una conformación neural única y propia ${ }^{11}$.

El Proyecto Cerebro Humano se pone en marcha en 2013 y se plantea, en principio, para una década. Es un proyecto médico-científico y tecnológico financiado por la Unión Europea, que tiene como fin reproducir tecnológicamente las características del cerebro humano, y de esta forma conseguir avances en el campo de la medicina, la neurociencia, la inteligencia artificial, o la robótica. Es un proyecto neurocientífico muy ambicioso, con subproyectos muy complejos, con más de 150 centros de investigación de la Unión Europea, y con presupuesto multimillonario, que seguro se va incrementando con el tiempo. Su objetivo es desarrollar tecnologías y métodos que posibiliten comprensión y explicación del funcionamiento cerebral. Para que este proyecto pueda desarrollarse es necesaria la investigación en nuevas tecnologías de supercomputación, que permitan utilizar la información en modelos informáticos y simulaciones del cerebro para identificar patrones y principios organizativos, de modo que se puedan integrar los resultados de miles de investigaciones con diversas tecnologías y distintos niveles de análisis, desde el molecular a los sistemas cerebrales $^{12}$.

Se ha iniciado con seis plataformas de investigación: neuroinformática, simulación del cerebro, computación de altas prestaciones, informática para la medicina, computación neuromórfica y neurorrobótica. La misión de la plataforma neuroinformática consiste en procesar la máxima cantidad de información e integrarla en una cartografía que comprenda distintos niveles del funcionamiento del cerebro humano: el genoma, la célula, las redes neuronales, áreas cerebrales y el cerebro entero. La información permitirá desarrollar la plataforma de simulación del cerebro. La plataforma médico-informática se encarga de desarrollar metodologías para el diagnóstico de enfermedades neurológicas, de forma rápida y personalizada. Esta plataforma trabajará con datos de miles de pacientes, en colaboración con hospitales y empresas farmacéuticas. La plataforma de computación se plantea lograr nuevas tecnologías inspiradas en el funcionamiento cerebral, por ejemplo, desarrollar chips que imiten redes neuronales. La plataforma neurorrobótica centrará sus trabajos en integrar la simulación de redes neuronales en robots con gran capacidad y flexibilidad de aprendizaje y memoria.

El proyecto europeo quiere aprovechar todos los datos para crear simulación del cerebro y robots de alto rendimiento. Los proyectos americanos y el proyecto europeo no tratan de competir para alcanzar la luna como sucedió en tiempos pasados, entre Estados Unidos y la Unión Soviética, por eso cabe esperar intercambio de información y colaboración entre investigadores. El problema a corto plazo está en la limitación de proceso y cálculo de los ordenadores, que no tienen capacidad para

11 Seung, S.: Conectoma. ¿Cómo las conexiones neuronales determinan nuestra identidad?, Barcelona, RBA, 2012.

12 https://www.humanbrainproyect.eu 
procesar la enorme cantidad de datos que los proyectos proporcionarán. Una de los superordenadores más potentes está en Japón, y es capaz de simular la actividad de mil ochocientos millones de neuronas conectadas a través de diez mil millones de sinapsis. Piénsese en lo lejos que está de los cien mil millones de neuronas y mil billones de conexiones del cerebro humano. Se espera que en la próxima década estén disponibles superordenadores mucho más potentes.

El proyecto BRAIN (Brain Research through Advacing Innovative Neorotechnologies) fue propuesto por el entonces presidente de EE UU, B. Obama, en 2013, con presupuesto multimillonario y para una década. Es una iniciativa catalogada como el equivalente del Proyecto del Genoma Humano. En este proyecto ha desempeñado un papel clave el español, investigador en la universidad de Columbia, Rafael Yuste ${ }^{13}$. Se propone descifrar la estructura cerebral para entender su funciones y procesos mentales: la percepción, la atención, el aprendizaje, la memoria, el lenguaje, el pensamiento, las emociones. El proyecto europeo y el norteamericano tienen objetivos parciamente diferentes, pero ambos constituyen apuestas muy ambiciosas, y dotadas de sobresalientes recursos institucionales, económicos y personales. La apuesta para resolver el problema fundamental de la neurociencia está en cómo se organizan y funcionan miles de millones de neuronas y billones de conexiones, hasta formar redes neuronales y sistemas cerebrales que posibilitan los procesos mentales. Para acercarse a estos objetivos se requieren instrumentos de alta tecnología y ámbitos diversos como la genética, la óptica, la nanotecnología, la biología molecular ${ }^{14}$.

Se están logrando avances tecnológicos muy importantes, como la posibilidad de estimular, mediante luz, neuronas específicas, incluso en las profundidades de los cerebros de animales. Los métodos optogenéticos combinan avances genéticos y ópticos, y se basan en la inserción en las neuronas de genes exógenos que codifican proteínas sensibles a la luz. La investigación se realiza en animales, como gusanos y ratones. Por ejemplo, en una investigación con la optogenética, para estudiar la amnesia, se utilizaron dos grupos de ratones, uno sano y otro genéticamente modificado, incapaz de recordar. Colocados en una caja donde recibían descargas eléctricas, los ratones sanos aprendían por condicionamiento operante a evitar esas descargas, pero los transgénicos olvidaban lo experimentado y no podían recordar. Se activó mediante optogenética las neuronas del hipocampo de los ratones amnésicos, y consiguieron superar la amnesia. También se investiga, en ratones, las funciones de la amígdala en la memoria de experiencias de miedo, y en las reacciones ante estímulos peligrosos y nocivos ${ }^{15}$.

La investigación optogenética está todavía en una fase experimental con animales, y necesitará más investigación y ensayos clínicos hasta que sea aplicable en humanos. Las posibilidades de la optogenética para la potenciación, recuperación de las capacidades y terapias son muy prometedoras pues, simplemente con luz y sin aplicar corrientes eléctricas, se conseguirían resultados positivos en el tratamiento de determinados trastornos, como fobias, trastornos obsesivo-compulsivos, estrés postraumático.

13 Se pueden consultar en la RED interesantes publicaciones y videos de Rafael Yuste.

14 https://www.braininitiative.org

15 Andero R, Daniel S, Guo JD, Bruner RC, Seth S, Marvar PJ, Rainnie D, Ressler KJ.: “Amygdala-Dependent Molecular Mechanisms of the Tac2 Pathway in Fear Learning”. Neuropsychopharmacology. 2016, May 26. doi: 10.1038/npp.2016.77. 
Otras técnicas para investigar e intervenir en las funciones cerebrales y procesos mentales son la estimulación magnética transcraneal y la estimulación cerebral profunda. La primera es una técnica no invasiva que estimula mediante campos magnéticos las redes neuronales de determinadas áreas cerebrales. Se han realizado estudios sobre memoria, déficit de atención e hiperactividad, funciones ejecutivas y se plantea si los resultados de mejoras podrían ser aplicables a personas normales. La estimulación cerebral profunda es una técnica muy invasiva, pues consiste en introducir electrodos en el interior del cerebro, conectados a una batería o neuroestimulador, para activar determinadas redes neuronales responsables de procesos mentales alterados. Se están realizando estudios e intervención con personas afectadas de patologías diversas, como parkinson, depresión, psicosis, trastorno bipolar ${ }^{16}$.

\section{Neurociencia en el proyecto humanista}

La gran mayoría de neurocientíficos considera los procesos mentales como propiedades que emergen del funcionamiento cerebral. Pero el gran problema sin resolver es explicar cómo surge la mente, la propia identidad, la conciencia de sí mismo y del mundo exterior, a partir de la materia física del cerebro. Explicar cómo cien mil millones de neuronas, conectadas entre sí con mil billones de conexiones, en una inmensa red o conectoma cerebral, originan todos los procesos mentales, es tarea pendiente para este siglo. Con palabras de Eric Kandel, el estudio biológico de la mente es más que una apasionante investigación científica con la intención de ampliar nuestro conocimiento del cerebro, y descubrir nuevas terapias para aquellas personas que padecen trastornos cerebrales. Los progresos realizados en el campo de la biología mental nos brindan la posibilidad de un nuevo humanismo, un humanismo que combine las ciencias, que se ocupan del mundo natural, con las humanidades, que tratan del significado de la experiencia humana. Este nuevo humanismo científico, basado en gran medida en la percepción de las diferencias que caracterizan la organización funcional del cerebro, cambiará considerablemente la manera de vernos a nosotros mismos y de ver a los demás. Cada uno de nosotros ya se siente único, gracias a la conciencia del sí mismo, pero tendremos una autentica confirmación biológica de nuestra individualidad. Esta constatación, a su vez, nos permitirá comprender de otra manera la naturaleza humana, y conocer y apreciar mejor tanto la humanidad individual como la compartida ${ }^{17}$.

El estudio de la mente como fenómeno natural, biológico, ha encontrado poderosas resistencias en la cultura occidental. Desde Descartes, que dividió el mundo en dos tipos de substancias, res cogitans y res extensa, el dominio de la ciencia se ha circunscrito a las cosas físicas, mientras que las mentales quedaban para otros saberes como la Filosofía o la Religión. En la Historia de la Filosofía y de las Ciencias ha sido problemático poner en relación los dos géneros de cosas, en

16 Zorzo, C., Banqueri, M., Higarza, S., Pernia, A., Arias, J.: "Estado actual de la estimulación magnética transcraneal y sus aplicaciones en psiquiatría”. Actas Españolas de Psiquiatría. 2019, 47 (3), 110-121. Vazquez-Bourgon, J., Martino, J., Sierra, M., et al.: "La estimulación cerebral profunda en el trastorno obsesivocompulsivo. Una revisión sistemática” Revista de Psiquiatría y Salud Mental. 2019, 12, pp. 37-51. Doi: org/10.1016/j.rpsm,2017.05.005.

17 Kandel, E.: La nueva biología de la mente, Barcelona, Paidós, 2019, pp. 16. 
apariencia tan diferentes. Por un lado, las cosas físicas, materiales, extensas, que interactúan causalmente con otras y producen efectos. Por otro, las cosas mentales, inmateriales, tales como los pensamientos, creencias, sentimientos, deseos. De ellas se dice que son mentales, subjetivas, más o menos conscientes. La materia y la mente parecen ser entidades totalmente distintas.

V. Ramachandran caracteriza al sí mismo con cinco atributos. Primero, la continuidad o impresión de un hilo ininterrumpido, que atraviesa todo el tejido de nuestra experiencia, con la sensación de pasado, presente y futuro. En segundo lugar, la idea de unidad y coherencia del sí mismo, pues a pesar de la diversidad de experiencias sensoriales, pensamientos y sentimientos, cada uno se experimenta como una persona única. En tercer lugar, una sensación de encarnación o propiedad del cuerpo en el que estamos anclados. En cuarto lugar, una sensación de agencia o idea de ser dueños de nuestros actos, lo que denominamos libre albedrío. Y quinto, la capacidad de reflexión, la conciencia que el sí mismo tiene de sí mismo.

Los atributos anteriormente citados pueden verse afectados por enfermedades cerebrales o intervenciones puntuales en el cerebro. Por ejemplo, si nos estimulan la corteza parietal derecha con un electrodo, mientras estamos conscientes, por un instante nos parecerá que flotamos cerca del techo y veremos nuestro cuerpo allá abajo. Habremos tenido una experiencia conocida como "fuera del cuerpo". La corporeidad, como uno de los atributos de nuestro sí mismo, es abandonado temporalmente. Otro ejemplo, la sensación de unidad de sí mismo. Es cierto que a veces hablamos de tener dos mentes, pero eso es más bien figura retórica. Incluso las personas aquejadas de lo que se conoce como trastorno de personalidad múltiple, o trastorno disociativo de identidad, no experimentan dos personalidades de forma simultánea. Las personalidades suelen turnarse. Incluso en el caso de paciente con cerebro dividido, cuyos dos hemisferios han sido desconectados quirúrgicamente, el paciente no experimenta subjetivamente tal desdoblamiento ${ }^{18}$.

Los procesos mentales, conscientes e inconscientes, son propiedades de sistemas neurales de organismos dotados de sistemas nerviosos complejos. Admitir que los procesos mentales surgen de la actividad neuronal no conlleva negar la presencia y recurso necesario de todo el organismo para tal actividad cerebral. Los procesos mentales son siempre de un organismo con un cerebro suficientemente desarrollado. El cerebro humano, mejor el sistema nervioso central, periférico y autónomo, que comprende más que el cerebro propiamente dicho, es un sistema indisociable del resto del cuerpo, integrado en el cuerpo mediante circuitos reguladores, bioquímicos, eléctricos, neurales.

Los procesos mentales y actividades neuronales se dan en un organismo que se mantiene vivo interactuando con el medio ambiente. Nunca puede interactuar el cuerpo sólo, ni el cerebro sólo. El ambiente es, en parte, producto de la actividad del organismo, y en el ser humano especialmente el ambiente sociocultural a su vez modifica el organismo, particularmente el cerebro mismo, gracias a la neuroplasticidad ${ }^{19}$.

Los procesos mentales no se reducen a elementos o propiedades físicas o químicas, sino que, además de requerir determinadas estructuras físico-químicas, exigen una peculiar estructura de carácter biológico, que se desarrolla y conforma desde un

Ramachandran, V.: Los laberintos del cerebro, Barcelona, La liebre de marzo, 2008, pp. 92-98.

Damasio, A.: El Error de Descartes, Barcelona, Crítica, 1996, pp.13-14 
programa genético propio de la especie en interacción con el medio. En el caso de los procesos mentales humanos ese medio es sociocultural. La sociedad y cultura son condiciones necesarias para el desarrollo de los procesos mentales superiores en el ser humano. Las propiedades mentales del cerebro no las poseen sus componentes celulares, ni las neuronas aisladas, sino que emergen como propiedades de sistemas neurales. Se trata de propiedades sistémicas, fruto de un largo pasado evolutivo de la especie -filogénesis-, y de un desarrollo individual -ontogénesis-. Más aún, las propiedades emergentes del cerebro son específicas y distintas de las propiedades de otros aparatos o subsistemas del organismo, como el aparato digestivo o circulatorio, por ejemplo. Percibir, sentir, pensar, recordar, imaginar, desear, querer, hablar, en fin, todos los procesos mentales son propiedades emergentes de sistemas neurales específicos e irreductibles a los componentes neurales o subcelulares de los mismos, o a la mera suma y agregado entre ellos ${ }^{20}$.

El cerebro humano es un sistema biológico. Su rasgo especial, la característica que lo diferencia de otros órganos o subsistemas biológicos del cuerpo, es su capacidad de producir y mantener toda la compleja variedad de nuestra vida mental. Todos los procesos mentales, la percepción, el aprendizaje, le razonamiento, la toma de decisiones, la resolución de problemas, las emociones y sentimientos, están crucialmente relacionados, de una manera u otra, con la conciencia. Además, todos esos grandes rasgos que son especiales de la mente, dependen de forma singular de la conciencia: la subjetividad, intencionalidad, racionalidad, voluntad, causación mental. El olvidarse de la conciencia es lo que da cuenta, más que cualquier otra cosa, a juicio de Searle, de la ausencia de frutos y la esterilidad de la psicología, de la filosofía de la mente y de las ciencias cognitivas ${ }^{21}$.

La conciencia es, a la vez, lo más próximo y familiar y lo más problemático. Nada hay que conozcamos de forma más directa e inmediata, pero resulta muy complicado articular ese conocimiento con el resto de nuestros conocimientos. Siguen sin respuestas preguntas importantes: ¿por qué existe la conciencia? ¿cómo funciona y para qué? ¿qué relación tiene con el cuerpo y más concretamente con el cerebro? Las respuestas son encontradas: unas son optimistas o problemáticas, considerando la conciencia como campo de investigación desde programas científicos; otras son pesimistas o mistéricas, al considerar la conciencia como misterio imposible de descifrar por la mente humana.

Una característica comúnmente aceptada de la conciencia es la "cualidad subjetiva de la experiencia", es decir, el carácter genitivo de la conciencia, como conciencia de alguien. Cuando percibimos, pensamos, sentimos y actuamos, además de tener conocimientos del mundo, se da un plus de conocimiento y experiencia, al sentirnos como agentes y experimentadores. Cuando un estado o proceso mental es consciente está ligado a una "sensación cualitativa". A estas sensaciones o experiencias cualitativas se las conoce también como cualidades fenoménicas, "qualia", experiencia fenomenológica o experiencia subjetiva. En la investigación de las experiencias conscientes, Chalmers diferencia entre los "problemas fáciles" y los "problemas duros". Los problemas fáciles no son triviales, muy al contrario, son los que han investigado las ciencias cognitivas, la Psicología, la Neurociencia y han

\footnotetext{
García García, E.: Mente y cerebro. Madrid, Síntesis, 2001, pp. 286-298

Searle, J.: El redescubrimiento de la mente, Madrid, Cátedra, 1996; Searle, J.: "Dos biólogos y un físico en busca del alma", Mundo Cientifico, 170, 1996, pp. 654-669
} 
proporcionado datos de gran interés. Entre los problemas fáciles está la investigación sobre los sistemas sensoriales, cómo se procesa la información en el cerebro, los sistemas neurales implicados, las alteraciones debidas a lesión cerebral; cómo se planifican, supervisan, controlan y realizan las acciones, la implicación de los sistemas neurales correspondientes, sus alteraciones; los sistemas neurales diferenciados en el procesamiento del lenguaje, los tipos de afasias debidos a lesiones cerebrales localizadas; los procesos cognitivos de atención, conceptualización, pensamiento, memoria; los procesos emocionales y sus trastornos, el llamado cerebro emocional.

Los problemas duros se plantean cómo los procesos neurales del cerebro dan lugar a la conciencia. Se refieren a esa dimensión, subjetiva, personal de los procesos mentales que permite que el sujeto los experimente como tal sujeto, como suyos y subjetivos. Los problemas fáciles versan sobre cómo se realizan funcionales mentales o comportamentales. Los problemas duros van más allá y se plantean por qué los procesos o funciones mentales y comportamentales van acompañados por la experiencia consciente. Los problemas fáciles tratan con datos de tercera persona, objetivos, observables, replicables; los problemas difíciles se las tienen que ver con datos de primera persona, privados, personales, subjetivos, irrepetibles ${ }^{22}$. Desde programas de investigación con supuestos naturalistas, la clasificación dicotómica en problemas fáciles y duros se relativiza, y las cuestiones a investigar se sitúan en un continuum de grados de dificultad, sin que a priori se establezcan zonas calificadas de mistéricas y al margen de la investigación. Así, se han formulado teorías de la conciencia a distintos niveles: subcelular (Penrose), neural (Crick), redes y sistemas neurales (Edelman, Llinás, Damasio, Dehaene), para mencionar algunas relevantes, que comentamos brevemente.

R. Penrose critica el modelo de ordenador y la teoría computacional para estudiar la mente, y propone el nivel explicativo en la mecánica cuántica. Las ciencias cognitivas suponen la existencia de un nivel de descripción de los procesos cognitivos situado entre los procesos conscientes y los procesos neurofisiológicos, bioquímicos y eléctricos, tratando de simular en ordenador lo que ocurre en ese nivel. Penrose cuestiona que las propiedades de la mente puedan comprenderse desde modelos computacionales, y niega que puedan ser objeto de simulación por ordenador. Las respuestas al problema de la conciencia no deben buscarse al nivel de las neuronas, pues al ser demasiado grandes son de incumbencia de la física clásica, sino a nivel subcelular, en las estructuras que posibilitan la célula, es decir en el citoesqueleto de la neurona. El citoesqueleto contiene unas microestructuras llamadas microtúbulos que desempeñan un papel determinante en el funcionamiento del sistema. La conciencia sería una manifestación de esas microestructuras microtubulares, en el orden de lo cuántico, que interaccionan con el nivel neuronal, en el orden de la física clásica ${ }^{23}$.

F. Crick era físico y biólogo, premio Nobel de Fisiología y Medicina en 1962, junto con J. Watson por el descubrimiento del ADN. Crick se sitúa en el nivel neuronal para dar cuenta de la conciencia. En su libro La búsqueda cientifica del alma ofrece los conocimientos disponibles sobre la estructura neuronal, a comienzos de la década de 1990. Su hipótesis revolucionaria que da subtítulo al libro plantea que las neuronas y sus componentes y moléculas asociadas, como los neurotransmisores,

\footnotetext{
Chalmers, D.: La mente consciente, Barcelona, Gedisa, 1999.

23 Penrose, R.: La nuevamente del emperador, Barcelona, Grijalbo, 1991; Penrose, R.: Las sombras de la mente, Barcelona, Crítica, 1996.
} 
son los responsables de la compleja actividad mental y sus diferentes grados de conciencia. F. Crick y su colega $\mathrm{Ch}$. Koch se han basado en las investigaciones sobre el sistema visual, un campo especialmente avanzado en neurociencia, y han formulado su teoría de la conciencia visual. Plantean que la conciencia visual consiste en una sincronización de actividad de neuronas espacialmente distribuidas en zonas diferentes del cerebro, que están implicadas en el procesamiento de información referente a distintas características del objeto, como forma, color, movimiento. La activación sincronizada de las neuronas a una frecuencia de unos 50 herzios por segundo sería el correlato cerebral de la conciencia visual. La clave de la conciencia, según Crick y otros neurocientíficos, como R. Llinàs, estaría en una interacción tálamo-cortical con una frecuencia de barrido de actuación de unos 50 ciclos por segundo. En todo caso, habría que dejar atrás las teorías cognitivo-computacionales de la conciencia y situarse en el andamiaje de la neurociencia para abordar con perspectivas de éxito la investigación ${ }^{24}$.

G. Edelman, premio Nobel de Fisiología y Medicina, en 1972, por sus investigaciones en anticuerpos, desarrolla una teoría de la conciencia en el nivel de redes y sistemas neuronales. El supuesto básico de la teoría es el "neodarwinismo neuronal" que pone en especial relación la estructura y organización cerebral con la teoría evolucionista. Distingue entre conciencia primaria, que comprende las sensaciones y percepciones, y la conciencia superior, con el lenguaje y la propia identidad personal. La conciencia superior del ser humano se desarrolla cuando, además de sentir y percibir, puede categorizar y representar simbólicamente la distinción entre lo propio y lo ajeno, formar una idea de sí mismo gracias a la interacción social, y mediante el lenguaje representar simbólicamente realidades ausentes, remontarse hacia el pasado, anticipar el futuro, moverse en mundos posibles, distanciarse de la experiencia presente inmediata, hacer cuestión de sí mismo y de su entorno ${ }^{25}$.

Antonio Damasio se sitúa en el nivel de los sistemas y redes neuronales para explicar la conciencia. Para avanzar en el conocimiento de la mente consciente, propone diferenciar dos aspectos: a) el conocimiento de algo, o lo que él denomina la película-en-el-cerebro y b) el conocimiento de alguien o la presencia del yo. Queda patente la correspondencia con las dos dimensiones de la intencionalidad de la conciencia. La primera metáfora -la película en el cerebro- hace referencia a la composición integrada y unificada de diversas imágenes sensoriales, visuales, auditivas, etc., que constituyen el espectáculo multimedia que llamamos mente. La segunda dimensión -el yo- concierne a la generación automática de un sentido de propiedad de esa película-en-el-cerebro. Ambas partes del problema se implican, la segunda anida en la primera. Separarlas es un mero procedimiento de utilidad en la investigación.

La película-en-el-cerebro lleva estudiándose desde al menos un siglo y medio, cuando Broca y Wernicke empezaron a "cartografiar" las áreas cerebrales implicadas en el lenguaje. Los estudios clínicos de cerebros parcialmente lesionados, y las actividades mentales afectadas, las investigaciones experimentales en laboratorios,

24 Crick, F.: La búsqueda cientifica del alma. Una revolucionaria hipótesis para el siglo XXI, Barcelona, Círculo de lectores, 1995; Llinás, R.: El cerebro y el mito del yo, Barcelona, Belacqua, 2003.

25 Edelman, G.: The remembered present. A biological theory of consciousness. New York, Basic Books, 1989. Edelman, G. y Tononi, G.: El universo de la conciencia, Barcelona, Crítica, 2002. 
las nuevas tecnologías de neuroimagen, están proporcionando conocimientos espectaculares sobre las diferentes áreas cerebrales y redes neuronales de una persona cuando está realizando determinados procesos mentales. Los conocimientos disponibles sobre las memorias, sus diferentes tipos, las estructuras neurales diferentes, las amnesias y sus sorprendentes disociaciones, los módulos neurales implicados en el lenguaje, las afasias, el cerebro emocional, todo ello está delimitando un nuevo continente a seguir explorando apasionadamente en las próximas décadas, según vayamos disponiendo de tecnologías más sofisticadas. Los conocimientos sobre la película-en-el-cerebro se imponen a las mentes más escépticas. Las evidencias sobre las bases nerviosas de la película-en-el- cerebro, el contenido de la conciencia, son concluyentes. Pero se sigue argumentando que la otra dimensión de la conciencia -la conciencia de alguien y experiencia del yo- es inabordable desde supuestos naturalistas ${ }^{26}$.

Los sistemas neurales del cerebro, a diferencia de otros tejidos como el corazón, hígado, etc., se caracterizan por su función de representación. Las neuronas representan entidades o acontecimientos que pueden darse en cualquier parte del cuerpo. Las células del cerebro se han diseñado evolutivamente para operar sobre otras. Surgieron como cartógrafos de la geografía del organismo y de los sucesos y procesos que acontecen en esa geografía. La evolución filogenética ha conquistado un cerebro cuya tarea consiste en representar directamente al organismo, e indirectamente a todo aquello con lo que el organismo interactúa. Estos mecanismos no son algo hipotético, se están identificando y residen en estructuras y sistemas neurales corticales y subcorticales del tronco cerebral, el hipotálamo, la corteza somatosensorial, el córtex cingulado. Tales reguladores de la vida representan también necesariamente a los estados en permanente cambio del organismo a medida que suceden. Así el cerebro dispone de unas estructuras que representan el estado del conjunto del organismo.

Pero estamos en un nivel biológico de control y equilibrio homeostático para mantener la vida. ¿Cómo pasar de esos reguladores biológicos al yo psicológico, a la experiencia de nuestra vida, nuestros pensamientos y sentimientos, sin suponer homúnculos que representen la realidad del sí mismo? El sentido del yo se basa en los mecanismos cerebrales que representan continuamente al mismo organismo. El cerebro utiliza sus estructuras de representación del organismo y de los objetos externos para crear una nueva representación del segundo orden. Esta representación indica que el organismo, cartografiado en el cerebro, está implicado en la interacción con un objeto, cartografiado a su vez en el cerebro. Tal representación de segundo orden acontece en determinadas estructuras nerviosas como el tálamo y la corteza cingulada. Este segundo nivel de representación aporta al organismo información de que el organismo es el propietario de ese proceso y posibilita la experiencia de un yo a quien le está pasando algo.

La conquista del yo es un último recurso de la evolución cerebral para ser más eficaz en la adaptación al medio. Así, un organismo autoconsciente dispone de más recursos para aprender de las experiencias, o de la película en el cerebro. La autoconciencia forma parte de esa película en la que está lo observado y el observador, lo experimentado y el experimentador, lo pensado y el pensador. No cabe un espectador externo cual homúnculo fantasma que observa la sala de proyección.

26 García García, E.: Somos nuestra memoria. Recordar y olvidar, Madrid, Emse Edapp, 2018. 
La experiencia del yo en cualquier tipo de experiencia surge como experiencia de lo que pasa en el organismo al interactuar con el mundo ${ }^{27}$.

S. Dehaene propone la teoría del "espacio de trabajo neuronal global" según la cual la conciencia es información compartida por la red global de todo el cerebro, que ha desarrollado muy complejas redes neuronales de larga distancia, entre la corteza prefrontal, temporal, parietal y occipital, para seleccionar información relevante y diseminarla por todo el cerebro. Así puede utilizarla eficientemente manteniéndola activa en las memorias y nombrándola gracias al lenguaje, permitiendo evaluarla y utilizarla para planificar nuestras acciones de acuerdo con metas futuras ${ }^{28}$.

Estudiar la mente humana, conciencia, subjetividad, será tarea apasionante para las próximas décadas. En este proyecto de humanismo científico, de comprensión y explicación de nuestra propia identidad, las diversas ciencias cognitivas, y particularmente la neurociencia, seguirán ofreciendo respuestas que, a su vez, plantearán nuevas preguntas. Somos seres en el mundo, resultado de un proceso evolutivo de millones de años. Nuestro cuerpo, nuestro cerebro, ha alcanzado la estructura actual, no desde un diseño a priori, sino como conquista tras una compleja y prolongada filogénesis, y ontogénesis cada vez mejor conocidas. Cada ser humano viene al mundo dotado con un cerebro maravilloso, que todavía nos reserva mayores sorpresas. Ese cerebro se estructura de una forma única e irrepetible en cada persona en interacción con el medio, particularmente el sociocultural. Se organiza y "cablea", estableciendo continuamente nuevas conexiones y redes neurales, dando lugar al conectoma propio de cada individuo.

\section{Neurociencia y posthumanismo}

Hemos comentado algunas características y objetivos de los programas de investigación en neurociencia que parece estarán vigentes en las próximas décadas, y que han sido y siguen siendo centrales en la tradición del pensamiento humanista. Pero desde los primeros años de este siglo, especialmente, se han dado grandes avances en campos tales como la ingeniería genética y biotecnología, la inteligencia artificial y computación, que plantean nuevos desafíos tanto científicos como filosóficos, dando lugar a un nuevo marco de pensamiento, que se ha denominado transhumanista y posthumanista. Las características de nuestra especie que compartimos todos los seres humanos: aproximadamente veintiún mil genes, organización funcional del cerebro, procesos mentales cognitivos, lingüísticos, emocionales podrían ser superados. Viviríamos el fin de esta etapa evolutiva humana, para adentrarnos en una etapa transhumana y posthumana. El ser humano dejaría de estar regido por las leyes de la evolución biológica, para seguir los planes y diseños que él establezca, pasando a ser el rector de su propia evolución.

El pensamiento posthumanista cuestiona la concepción de identidad humana esencialista, el ser humano único y superior, la medida de todas las cosas, y considera una etapa de transición transhumana hacia la condición posthumana, en la

\footnotetext{
27 Damasio, A.: La sensación de lo que ocurre. Cuerpo y emoción en la construcción de la conciencia. Barcelona, Debate, 2001; Damasio, A.: Y el cerebro creo al hombre. Barcelona, Destino, 2010; Damasio, A.: El extraño orden de las cosas, Barcelona, Destino, 2018.

28 Dehaene, S.: La conciencia en el cerebro, Buenos Aires, Siglo XXI, 2015.
} 
que se superarán los límites de la naturaleza biológica del hombre. El pensamiento posthumanista se plantea traspasar los límites biológicos de la naturaleza humana, superar las limitaciones del código genético, genoma, y de la organización funcional del cerebro humano, conectoma.

El pensamiento transhumanista se puede concretar en los siguientes puntos: a) En el futuro, la humanidad cambiará de forma radical por las tecnologías. Se prevé la viabilidad de rediseñar la condición humana, incluyendo parámetros tales como lo inevitable del envejecimiento, las limitaciones de las mentes humanas, el sufrimiento, y hasta nuestro confinamiento al planeta Tierra. b) Aceptando las nuevas tecnologías, tendremos una mayor probabilidad de utilizarlas para nuestro provecho, mejor que si las condenamos y prohibimos. c) Los transhumanistas defienden el derecho moral de aquellos que deseen utilizar la tecnología para ampliar sus capacidades mentales y físicas, y para mejorar su control sobre sus propias vidas. d) De cara al futuro, es obligatorio tener en cuenta la posibilidad de un progreso tecnológico dramático. Sería trágico si no se materializaran los potenciales beneficios a causa de una tecnofobia injustificada y prohibiciones innecesarias. Por otra parte, también sería trágico que se extinguiera la vida inteligente a causa de algún desastre o guerra ocasionados por las tecnologías avanzadas. e) Necesitamos crear foros donde la gente pueda debatir racionalmente qué debe hacerse, y un orden social en el que las decisiones razonables puedan llevarse a cabo. f) El transhumanismo defiende el bienestar de toda conciencia (sea en mentes artificiales, humanas, animales no humanos, o posibles especies extraterrestres), y acepta principios del humanismo laico. El transhumanismo dice no apoyar ni apoyarse en ningún grupo o plataforma política determinada ${ }^{29}$.

El transhumanismo sigue conservando valores clásicos del humanismo, como el puesto del hombre en el cosmos, la autoconciencia, el sí mismo personal irreductible a lo material, la sacralización de la voluntad y el libre albedrio. En la etapa transhumanista nuestra especie todavía mantendría las características esenciales que nos hace humanos ${ }^{30}$, pero incrementando todas las capacidades físicas y mentales de las personas, previniendo limitaciones y trastornos, manteniendo la autonomía y control frente a los riesgos y amenazas de los avances en inteligencia artificial y computación.

Hace cien mil años el homo sapiens compartía el planeta tierra con, al menos, cinco especies humanas: Neandertales, Denisovanos, Homo Floresiensis, Homo Luzoniensis y Homo Erectus. La mente del homo sapiens, gracias a una revolución cognitiva y afectiva, pasó de ser una especie más a la única dueña del mundo. La mente mejorada del sapiens consiguió un acceso al ámbito intersubjetivo, especialmente gracias al lenguaje, que nos permitió crear dioses y empresas, construir ciudades e imperios, inventar la escritura y el dinero, la energía atómica y la llegada a la luna. Hasta donde sabemos, esta revolución que sacudió la tierra fue resultado de unos pocos y pequeños cambios en el ADN de los sapiens, y de nuevas interconexiones en las redes neuronales de sus cerebros, al interactuar con los productos culturales. Cabe pensar, entonces, que nuevos cambios en nuestro genoma y conectoma podrían poner en marcha una segunda revolución mental. Los cambios mentales de la primera revolución cognitiva y afectiva dieron al homo sapiens acceso al ámbito

https://transhumanismo.org

30 Gazzaniga, M.: Qué nos hace humanos, Barcelona, Paidós, 2010. 
intersubjetivo y nos convirtieron en los dueños de la tierra. Una segunda revolución cognitiva podría darnos acceso a nuevos ámbitos inimaginables y transformarnos en los amos de la galaxia, convertirnos en otra especie: el Homo Deus ${ }^{31}$. Yuval Noah Harari identifica tres vías para avanzar en el camino: ingeniería biológica, ingeniería de los ciborgs, ingeniería de vida inorgánica ${ }^{32}$.

La ingeniería biológica es la intervención humana a nivel biológico destinada a modificar y optimizar la necesidades y capacidades de los organismos. Se trata de intervenir las leyes de la evolución, mediante diseños que plantean los científicos en sofisticados laboratorios. La ingeniería genética se propone modificar el código genético de los organismos y por tanto alterar sus capacidades mentales y comportamientos. La ingeniería genética plantea graves cuestiones éticas y políticas. Los activistas de derechos de los animales se oponen radicalmente al sufrimiento generado en laboratorios que estudian los modelos animales, como diseñar ratones más inteligentes o más valientes, las modificaciones genéticas en los animales de granja para producir más recursos. Los activistas por los derechos humanos alertan de mundos apocalípticos de superhombres y siervos. La ingeniería genética no sólo plantea transformar genomas de animales vivos, también pretende revivir animales o humanos extinguidos. Conocido el genoma del Neandertal se ha planteado poder revivir esa especie.

Recientemente David Liu y colaboradores han descubierto una nueva técnica para modificar con una precisión sin precedentes la información genética de los seres vivos. Las células humanas tienen su manual de instrucciones escrito con cuatro letras: adenina, guanina, timina, citosina (ATTGCTGAA...) en dos metros de ADN plegados de manera asombrosa. Las herramientas de edición genética, como la técnica CRISPR que ha revolucionado los laboratorios desde 2012, son capaces de buscar una secuencia concreta de letras y cortarla de manera específica con una especie de tijeras moleculares, insertando nueva información como si fuera un procesador de textos. El problema es que, a menudo, la operación falla y se generan mutaciones no deseadas. Como resultado se producen la mayor parte de las 75.000 variantes genéticas humanas asociadas a enfermedades que no se pueden corregir actualmente en el laboratorio, según los cálculos del equipo de Liu. Su método, afirman, puede reparar el $90 \%$ de esas mutaciones no deseadas ${ }^{33}$.

La ingeniería de ciborgs es una tecnología que modifica las leyes naturales de la vida y permite crear seres que combinan partes orgánicas e inorgánicas. De alguna manera muchas personas en la actualidad ya son biónicas, porque complementan o superan las limitaciones de los sentidos orgánicos con prótesis o dispositivos inorgánicos, como gafas e implantes intraoculares, audífonos e implantes cocleares, marcapasos, manos y pies biónicos, etc. Continuamente tenemos noticias de avances espectaculares en el diseño de estos componentes inorgánicos que permiten superar las carencias o limitaciones de los sentidos, la motricidad, y otros sistemas como cardiovascular, respiratorio, digestivo. Personas que han perdido alguna extremidad y que reciben otras biónicas. El principio básico es accionar esos dispositivos, cada vez más normalizados, con los procesos mentales. Las señales neuronales,

\footnotetext{
Harari, Y. N.: Homo Deus. Breve historia del mañana, Barcelona, Debate, 2016., pp. 383-400.

Harari, Y. N.: Sapiens. De animales a Dioses, Barcelona, Debate, 2014, pp. 438-454.

Anzalone, A., Liu, D. et al.: "Search-and-replace genome editing without double-strand breaks or donor DNA", Nature, 2019. doi: 10.1038/s41586-019-1711-4.
} 
los potenciales eléctricos que acompañan nuestros pensamientos y decisiones son traducidas por micrordenadores en instrucciones, y los brazos o piernas se mueven. Tenemos investigaciones con macacos en cuyos cerebros se han implantado electrodos que captan señales eléctricas y las transmiten a dispositivos externos. Una mona, llamada Aurora, aprendió a controlar mediante su mente un brazo biónico separado, a la vez que movía sus dos brazos orgánicos. Otro macaco, Idoya, controló unas piernas biónicas en Kioto, desde su silla en Carolina del Norte. Las piernas pesaban veinte veces el peso de Idoya.

A personas que padecen el síndrome de enclaustramiento, por lo que han perdido la capacidad de mover su cuerpo y sólo pueden parpadear, pero conservan intactas sus capacidades cognitivas, para conseguir comunicarse, se les ha implantado electrodos en el cerebro que captan señales neuronales y gracias a dispositivos que traducen esas señales en movimientos, como un cursor desplazándose en una pantalla y más recientemente mediante palabras ${ }^{34}$. Se están diseñando modelos de interfaz cerebroordenador en las dos direcciones que permitan a los ordenadores leer las señales eléctricas del cerebro, y a la vez el cerebro pueda leer las señales del ordenador. Harari se pregunta qué sucederá si estas interfaces se llegan a utilizar para conectar a internet, o para conectar varios cerebros entre sí, en una especie de internet cerebral; qué ocurrirá en las capacidades humanas, la memoria humana, la conciencia y la identidad del hombre, si el cerebro tiene acceso directo a un banco de memoria colectivo ${ }^{35}$.

Otras tecnologías plantean abandonar el cerebro para crear seres inorgánicos, y pasar de seres vivos basados en el carbono, a seres inorgánicos basados en el silíceo y la computación cuántica. La ingeniería de seres inorgánicos puede cambiar las leyes de la vida y producir seres completamente inorgánicos, gracias a los extraordinarios avances en inteligencia artificial y computación cuántica. Estamos a las puertas de una nueva revolución tecnológica, protagonizada por el aprendizaje automático de las máquinas, la computación cuántica y el $5 \mathrm{G}$ e internet de las cosas. La combinación de estos avances planteará nuevas oportunidades y a la vez desafíos. Muchos programadores sueñan con crear programas que puedan aprender, y que evolucionen de manera completamente independiente de su creador y, más aún, que evolucionen en direcciones que ningún ser humano podría haber previsto.

La propuesta que amenaza con cortar el cordón umbilical con el humanismo y el transhumanismo es el dataísmo, la religión de los datos. El dataísmo sostiene que el universo, tanto animado como inanimado, consiste en almacenamiento y procesamiento de datos. Las estructuras biológicas, políticas, sociales y culturales humanas serían sistemas de procesamiento de datos. Este nuevo marco es resultado de los avances espectaculares en dos campos: la biología y la informática. El dataísmo unifica ambos campos bajo el dominio de los algoritmos. Hasta ahora los datos, las informaciones eran el primer paso para generar conocimiento, y el conocimiento exigía criterios para ordenar, evaluar y criticar las informaciones, incluso para someter a revisión los criterios mismos. Pero en la actualidad los datos y las informaciones alcanzan tales flujos, que ninguna mente humana puede asimilar y evaluar, de ahí que encarguemos el procesamiento a los algoritmos y computación,

34 Nicolelis, M.: Mas allá de nuestros límites: Los avances en la conexión de cerebros y máquinas, Barcelona, RBA, 2012.

35 Harari, Y. N.: Sapiens. De animales a dioses, Barcelona, Debate, 2016, pp. 446-448. 
que se avecina cuántica.

$\mathrm{Si}$ los avances biotecnológicos equiparan las experiencias humanas a procesamiento de datos, el dataísmo socava nuestra principal fuente de autoridad y sentido, que en la tradición humanista está en la esencia humana, la dignidad, la voluntad, la libre elección. Los humanistas ilustrados sostenían que Dios es producto de la mente humana, de la imaginación humana. El dataísmo va más allá y afirma que la mente humana, la imaginación humana, los pensamientos y emociones, la toma de decisiones son producto de los algoritmos. En el siglo XVIII, el humanismo dejó de lado a Dios, al pasar de una cosmovisión teocéntrica a una antropocéntrica. En el siglo XXI, el dataísmo podría dejar de lado los humanos y pasar de una visión antropocéntrica a una visión datacéntrica, la era de Big Data e Internet de Todas las $\operatorname{Cosas}^{36}$.

Hace setenta mil años el homo sapiens era un animal insignificante, ocupado en sobrevivir. En los milenos siguientes se transformó en el amo de todo, y el terror del ecosistema. Y podría convertirse en homo deus, con capacidades cuasi divinas de creación y de destrucción. Sin duda somos más poderosos de lo que nunca fuimos, pero tenemos poca idea de qué hacer con ese poder, y más grave aún, somos más irresponsables que nunca, causando estragos a nuestros socios animales y al ecosistema que nos rodea, buscando nuestra comodidad y nuestra diversión, pero sin encontrar satisfacción. ¿Y hay algo más peligroso que unos dioses insatisfechos, que no saben lo que quieren? Con esta interrogación finaliza Harari su libro Sapiens.

Probablemente la revolución dataísta llevará unas cuantas décadas o siglos, o quizá no llegue a darse en sus formulaciones más extremas, porque el futuro es imprevisible. No podemos saber con certeza que ocurrirá dentro de veinticinco, cincuenta o cien años, cómo será nuestra vida, la familia, los trabajos, el ocio, etc. Pero deberíamos tomarnos en serio que las próximas etapas de la historia puedan traer transformaciones, no sólo tecnológicas, sino también otras más fundamentales en la conciencia e identidad humanas. Esta cuestión de la mejora humana, de los cambios esenciales de nuestra especie, de la sostenibilidad de la vida en nuestro planeta, empequeñecen los debates que en la actualidad preocupan a filósofos, científicos o políticos. Si preguntamos a los científicos por qué estudian el genoma, intentan conectar un cerebro a un ordenador, o intentan crear una mente dentro una máquina, obtendríamos siempre la misma respuesta, que se hace para curar enfermedades y salvar vidas. Estas son las justificaciones que nadie discute. Pero las implicaciones van mucho más allá, y se plantean hasta qué punto podemos manipular nuestros pensamientos, nuestras emociones y nuestros deseos, controlar la voluntad y libre albedrio. Objetivos a largo plazo, e incluso a medio, no están en el debate público, ni en las agendas políticas de los gobiernos que son meros administradores, preocupados por gestionar los recursos para garantizar con justicia y equidad, en el mejor de los casos, niveles de calidad en trabajo, vivienda, salud, educación, jubilación; pero ya no dirigen porque no saben, ni nadie lo sabe, cómo van a ser las sociedades y los estados después de 30 años, a mediados del siglo.

Para el posthumanismo llegará el momento en el que el homo sapiens ya habrá completado su ciclo, y tendrá que pasar el relevo a unas entidades completamente nuevas, unas realidades inorgánicas. Inteligencia artificial y conciencia biológica se están disociando a gran velocidad. Tendremos que plantearnos ese gran problema que

36 Harari, Y. N.: Homo Deus. Breve historia del mañana, Barcelona, Debate, 2016, pp. 420-430. 
es extremadamente difícil, por cuanto no sabemos mucho sobre nuestros procesos mentales y los niveles de conciencia, y la evolución de la inteligencia artificial y la computación cuántica se presenta como un continente a explorar. Las ciencias de la vida y de la salud se preocupan cada vez más, no sólo de curar enfermedades, sino de mejorar a los sanos, buscando mejorar el cerebro y la mente. Es el momento de intervenir en nosotros mismos, nuestro cuerpo y especialmente nuestro cerebro. Estamos consiguiendo conocimientos, capacidades y recursos para lograr nuevos procesos mentales y estados de consciencia, pero carecemos de un mapa de esos territorios inexplorados.

\section{Conclusiones}

La Declaración Universal de los Derechos Humanos, las constituciones nacionales, los programas médicos de los estados, todos reconocen que una sociedad más desarrollada, justa y feliz, debe conceder a todos sus miembros un tratamiento médico adecuado y de calidad. Pero esto podía estar muy bien mientras la medicina se preocupa de evitar las enfermedades y curar a los enfermos, pero puede suceder algo muy distinto cuando las ciencias de la vida y la medicina se preocupen de incrementar las capacidades humanas. Puede que todos los humanos no tengan acceso a estas capacidades mejoradas, y habría distintas clases de seres. Y así, podemos estar a las puertas de un mundo más desigual que nunca en el pasado. Las nuevas tecnologías no estarán a disposición de todos los humanos, y dependerán de su nivel económico, estableciendo clases superiores e inferiores.

Las capacidades tecnológicas ya disponibles, y especialmente las que se vislumbran en el horizonte, pueden amenazar la supervivencia de nuestra especie, la integridad genética, las condiciones ambientales, todo lo que nos hace humanos, la vida misma en nuestro planeta. Ocupan un primer plano cuestiones éticas radicales, como si debe seguir viviendo el ser humano que conocemos, resultado del proceso evolutivo, si debemos respetar la herencia genética, la filogénesis y ontogénesis de nuestro cerebro y los procesos mentales. El pensamiento posthumanista debería someterse a la información y debate, no sólo académico sino también público. Es necesario explicitar los supuestos que están a la base de programas de investigación en grandes empresas biotecnológicas y laboratorios de élite, pero también los mundos felices que se imaginan y venden en medios de masas.

Las nuevas tecnologías, la simbiosis de los avances en inteligencia artificial, aprendizaje automático y tecnologías biomédicas plantean dilemas morales muy complejos y urgentes. Las propuestas que se ofrecen para responder a los desafíos sociales, éticos, legales son dispares, de ahí la necesidad de debates públicos bien informados. Los procesos de información, diálogo y crítica deben estar basados en valores. El Informe sobre los Principios Asilomar en Inteligencia Artificial y la Declaración del Grupo Europeo sobre Etica de la Ciencia y Nuevas Tecnologías, con el título "Inteligencia artificial, robótica y sistemas autónomos" ${ }^{37}$ hacen propuestas

37 Grupo de estudio evaluación de la Tecnología de la Digitalización: Informe sobre los Principios Asilomar en Inteligencia Artificial, Berlín, 2018.

Grupo Europeo sobre Ética de la Ciencia y Nuevas Tecnologías.: Inteligencia artificial, Robótica y Sistemas Autónomos, Bruselas, 2018. 
para lograr un marco ético y legal común, internacionalmente reconocido, para el diseño, producción y gobernanza de la inteligencia artificial, la robótica y los sistemas autónomos. Las declaraciones se fundamentan en un conjunto de principios éticos, basados en los valores establecidos de los Tratados de la Unión Europea y en la Carta de Derechos Fundamentales, y también recogen iniciativas de asociaciones de profesionales y organismos varios ${ }^{38}$.

Se resalta que las herramientas cognitivas más poderosas son también las más opacas, puesto que sus acciones han dejado de ser programadas linealmente por humanos. En este sentido, se destacan algunos ejemplos. Google Brain desarrolla una IA que al parecer construye otras de su misma naturaleza mejor y más rápidamente que los humanos. AlphaZero puede autoejecutarse y pasar en cuatro horas de ser completamente ignorante de las reglas del ajedrez a alcanzar el nivel del campeón del mundo. Estos dos casos ilustran que el aprendizaje profundo y los llamados "enfoques de redes generativas antagónicas" hacen posible que las máquinas se "enseñen" a sí mismas nuevas estrategias y adquieran nuevos elementos para ser incorporados en sus análisis. De esta forma, las acciones de estas máquinas se vuelven indescifrables y escapan del escrutinio humano. Esto se debe, en primer lugar, a que resulta imposible averiguar cómo se generan los resultados más allá de los algoritmos iniciales. En segundo lugar, porque el rendimiento de estas máquinas se basa en los datos utilizados durante el proceso de aprendizaje y estos pueden no estar disponibles o ser inaccesibles. Y además pueden generar errores, sesgos y prejuicios que quedaran enraizados en el sistema, que los reproduce y amplifica.

La Declaración sobre inteligencia artificial, robótica y sistemas autónomos propone un conjunto de principios éticos como: A) Dignidad humana. El respeto a la dignidad no debe ser violado por tecnologías autónomas. Es preciso establecer límites para evitar que se haga creer a las personas que están tratando con seres humanos, cuando en realidad lo hacen con algoritmos y máquinas. B) Autonomía. El concepto "autonomía" se refiere a la capacidad que tienen las personas para legislarse a sí mismas, para formular, pensar y elegir normas que ellos mismos deben cumplir. Este concepto abarca el derecho a ser libre para establecer estándares, objetivos y propósitos de vida propios. La autonomía, en el sentido relevante de la palabra, sólo puede ser atribuida a los seres humanos. De ahí que resulte inapropiado utilizar el término "autonomía" para referirse a meros artefactos, aunque se trate de sistemas adaptativos muy avanzados o incluso "inteligentes". Si ningún sistema inteligente puede ser considerado autónomo en el sentido ético y legal, tampoco puede ser considerado titular de la moralidad y dignidad. C) Responsabilidad. El principio de responsabilidad debe ser fundamental en la investigación e implementación de la IA. Los sistemas "autónomos" sólo deberían desarrollarse y aplicarse, si sirven al bienestar social y ambiental a nivel global. Establecer dicho bienestar requiere procesos democráticos deliberativos. D) Justicia, equidad y solidaridad. Se debe

38 https://standards.ieee.org/news/2016/ethically_aligned_design.html

https://www.itu.int/en/ITU-T/AI/Pages/201706-default.aspx

https://www.aies-conference.com/2020/

https://www.partnershiponai.org

https://openai.com

https://futureoflife.org/ai-principles

https://nouvelles.umontreal.ca/en/article/2017/11/03/montreal-declaration-for-a-responsible-development-ofartificial-intelligence 
facilitar la igualdad de acceso a los benéficos y ventajas de las tecnologías. Y se deben evitar los sesgos y discriminaciones en las bases de datos. Esta igualdad y equidad debe alcanzarse entre diferentes sociedades y en el seno de cada una de ellas. E) Democracia. Las decisiones clave sobre a la regulación de la IA, específicamente sobre su desarrollo y aplicaciones, deben ser el resultado de procesos de debate democrático y participación ciudadana. Cooperación global y procesos de diálogo público asegurarán que estas decisiones sean inclusivas, informadas y con visión de futuro. F) Estado de derecho y rendición de cuentas. El estado de derecho, el acceso a la justicia y el derecho de recibir una compensación y un juicio justo, proporcionan el marco necesario para garantizar la observancia de las normas de derechos humanos. Esto incluye la protección contra la violación de los derechos humanos por parte de los sistemas "autónomos", por ejemplo, la seguridad o la privacidad. G) Seguridad, protección e integridad física y mental. La seguridad y la protección de los sistemas "autónomos" se concretan en: la seguridad externa, que se ofrece al entorno y a los usuarios; la confiabilidad y la robustez interna, por ejemplo, contra la piratería; y la seguridad emocional, que se refiere a la interacción humano-máquina. H) Protección de datos y privacidad. En una era de recopilación generalizada y masiva de datos a través de tecnologías digitales de la comunicación, el derecho a la protección de la información personal y el derecho a la privacidad están siendo cuestionados. I) Sostenibilidad. Se debe garantizar los prerrequisitos fundamentales para la vida en nuestro planeta, la conservación del medioambiente para las generaciones futuras. Las estrategias para evitar que las futuras tecnologías afecten negativamente la vida humana y la naturaleza necesitan fundamentarse en políticas que prioricen la protección del medio ambiente y la sostenibilidad.

La biotecnología, la inteligencia artificial, la robótica y los sistemas "autónomos", el internet de todas las cosas, pueden traer prosperidad, contribuir a la calidad de vida, y ayudar a alcanzar los ideales morales y los objetivos socioeconómicos europeos. Lo anterior es posible, solo si estas tecnologías se diseñan y se implementan de forma sensata. Pero los cambios que vivimos están creando en el mundo sociedades muy fragmentadas. Unas disponen de las condiciones vitales adecuadas, y reciben la educación necesaria para contribuir al desarrollo del hiperconectado mundo actual, y otras carecen de tales condiciones, y viven en una peligrosa y creciente marginación. Los valores señalados para el marco europeo son más necesarios a nivel de humanidad, cuando gran parte de los más de siete mil millones de personas viven hoy en condiciones subdesarrolladas. Mil millones sobreviven en extrema pobreza, sin acceso a agua potable, y sólo aspiran a una vida, en la que estén satisfechas sus necesidades más básicas de vivienda, salud y educación. Desde esta perspectiva los debates y propuestas posthumanistas serían más propios de las preocupaciones y aspiraciones de élites minoritarias, que tienen más que satisfechas sus necesidades básicas.

\section{Referencias bibliográficas}

Andero R, Daniel S, Guo JD, Bruner RC, Seth S, Marvar PJ, Rainnie D, Ressler KJ.: "Amygdala-Dependent Molecular Mechanisms of the Tac2 Pathway in Fear Learning". Neuropsychopharmacology. 2016, May 26. doi: 10.1038/npp.2016.77. 
Anzalone, A., Liu, D. et al.: Search-and-replace genome editing without double-strand breaks or donor DNA, Nature, 2019, doi:10.1038/s41586-019-1711-4.

Bear, M., Connors, B. y Paradiso, M.: Neuroscience, exploring the brain, Philadelphia, Lippincott Williams, 2016.

Cortina, A.: Guia Comares de Neurofilosofía práctica, Granada, Comares, 2012.

Crick, F.: La búsqueda cientifica del alma. Una revolucionaria hipótesis para el siglo XXI, Barcelona, Círculo de Lectores, 1995.

Chalmers, D.: La mente consciente, Barcelona, Gedisa, 1999.

Changeux, J. P.: Sobre lo verdadero, lo bello y el bien. Un nuevo enfoque neuronal, Madrid, Katz Editores, 2010.

Damasio, A.: El Error de Descartes. Barcelona, Critica,1996.

Damasio, A.: La sensación de lo que ocurre. Cuerpo y emoción en la construcción de la conciencia. Barcelona, Debate, 2001.

Damasio, A.: Y el cerebro creó al hombre, Barcelona, Destino, 2010.

Damasio, A.: El extraño orden de las cosas, Barcelona, Destino, 2018.

Dehaene, S.: La conciencia en el cerebro, Buenos Aires, Siglo XXI, 2015.

Edelman, G.: The remembered present. A biological theory of consciousness. New York, Books, 1989.

Edelman, G. y Tononi, G.: El universo de la conciencia, Barcelona, Crítica, 2002.

García García, E.: Mente y cerebro. Madrid, Síntesis, 2001.

García García, E.: "Neuropsicología y educación. De las neuronas espejo a la teoría de la mente", Revista de Psicología de la Educación, 1, 3, 2008.

García García, E.: "Desarrollo de la mente: filogénesis, sociogénesis y ontogénesis", en M. Maceiras y L. Méndez (eds), Ciencia e investigación en la sociedad actual, Salamanca, San Esteban, 2010.

García García, E.: Somos nuestra memoria. Recordar y olvidar, Madrid, Emse Edapp, 2018.

Gazzaniga, M.: Qué nos hace humanos, Barcelona, Paidós, 2010.

Glasser, M. et al.: "A multi-modal parcellation of human cerebral cortex", Nature, 536, 2016, pp. 171-78. doi:10.1038/nature18933.

Grupo de estudio evaluación de la Tecnología de la Digitalización: Informe sobre los Principios Asilomar en Inteligencia Artificial, Berlín, 2018.

Grupo Europeo sobre Ética de la Ciencia y Nuevas Tecnologías.: Inteligencia artificial, Robótica y Sistemas Autónomos, Bruselas, 2018.

Harari, Y. N.: Homo Deus. Breve historia del mañana, Barcelona, Debate, 2016.

Harari, Y. N.: Sapiens. De animales a Dioses, Barcelona, Debate, 2014.

Illes, J.: "Neurologisms", American Journal of Bioethics, 9, 9, 1, 2009. doi:

10.1080/152651609031192557.

Kandel, E.: En busca de la memoria, Buenos Aires, Katz, 2007.

Kandel, E.; Schwartz, J. y Jessell, T.: Neurociencia, Madrid, Prentice Hall, 2000.

Kandel, E.: La nueva biología de la mente, Barcelona, Paidos, 2019.

Llinás, R.: El cerebro y el mito del yo, Barcelona, Belacqua, 2003

Mora, F.: Neurocultura, Madrid, Alianza, 2007.

Nicolelis, M.: Mas allá de nuestros límites: Los avances en la conexión de cerebros y máquinas, Barcelona, RBA, 2012.

Penrose, R.: La nuevamente del emperador, Barcelona, Grijalbo, 1991.

Penrose, R.: Las sombras de la mente, Barcelona, Crítica, 1996.

Ramachandran, V.: Los laberintos del cerebro, Barcelona, La liebre de marzo, 2008.

Ramachandran, V.: Lo que el cerebro nos dice, Barcelona, Paidós, 2012. 
Searle, J.: El redescubrimiento de la mente, Madrid, Cátedra, 1996.

Searle, J.: "Dos biólogos y un físico en busca del alma”, Mundo Cientifico, 170, 1996.

Rizzolatti, G.: "The mirror neuron sysrtem and imitation", en S. Hurley y N. Chatter (comp.). Perspectives on imitation: from Neuroscience to Social Science, Cambridge MA, MIT Press, 2005.

Rizzolatti, G. y Sinigaglia, C.: Las neuronas espejo, Barcelona, Paidós, 2006.

Seung, S.: Conectoma. ¿Cómo las conexiones neuronales determinan nuestra identidad?, Barcelona, RBA, 2012.

Tomasello, M.: Los orígenes culturales de la cognición humana, Buenos Aires, Amorrortu, 2007.

Vazquez-Bourgon, J., Martino, J., Sierra, M., et al.: "La estimulación cerebral profunda en el trastorno obsesivo-compulsivo. Una revisión sistemática" Revista de Psiquiatría y Salud Mental. 2019, 12, pp. 37-51. doi, org/10.1016/j.rpsm,2017.05.005.

Zorzo, C., Banqueri, M., Higarza, S., Pernia, A., Arias, J.: "Estado actual de la estimulación magnética transcraneal y sus aplicaciones en psiquiatría" Actas Españolas de Psiquiatría. 2019, 47 (3), 110-121.

https://www.braininitiative.org/

https://www.humanconnectomeproject.org

https://www.humanbrainproject.eu/en/

https://transhumanismo.org/

https://standards.ieee.org/news/2016/ethically_aligned_design.html

https://www.itu.int/en/ITU-T/AI/Pages/201706-default.aspx

https://www.aies-conference.com/2020/

https://www.partnershiponai.org/

https://openai.com/

https://futureoflife.org/ai-principles/

https:/www.canasean.com/the-montreal-declaration-for-the-responsible-development-ofartificial-intelligence-launched/ 